\title{
Wirksame Führung durch Haltung
}

\section{Zusammenfassung}

Die zentrale Aussage dieses Buches ist: Wirksame Führung bedarf einer Haltung. Dies ganz grundsätzlich und in einer noch größeren Bedeutsamkeit vor dem Hintergrund einer notwendig werdenden, neuen Führungskultur. (s. Kap. 2.)

Ich habe schrittweise ausgeführt, dass mentale Haltungen ein prägender Anteil unserer Persönlichkeit sind und Verhalten beeinflussen. Das Embodiment wiederum zeigt die Wechselwirkung von mentaler und körperlicher Haltung auf und öffnet so einen Weg zur Bewusstwerdung und nachhaltigen Veränderung von Verhaltensweisen. Dabei geht es nicht um ein Richtig oder Falsch, sondern um ein tiefes Erkennen des eigenen Selbst.

Dieses Erkennen kann als Reifung der Persönlichkeit oder personales Wachstum bezeichnet werden. Führungskräfte stehen in der besonderen Verantwortung, die Herausforderungen für eine lebenswerte Zukunft im Mikrokosmos ihres Unternehmens zu gestalten. Hierbei hilft der Körper. Seien Sie achtsam Ihrer Haltung gegenüber und gehen Sie dafür

\section{„Raus aus dem Kopf, rein in den Körper!“}

